\title{
Laparoscopic Versus Open Surgery for Rectal Cancer in Elderly Patients
}

\author{
Zexian Chen ${ }^{1}$, Xiaosheng He ${ }^{1}$, Juanni Huang ${ }^{2}$, Xiaojian Wu ${ }^{1}$, Ping Lan ${ }^{1}$ \\ ${ }^{1}$ Department of Colorectal Surgery, the Sixth Affiliated Hospital, Sun Yat-sen University, Guangzhou, China \\ ${ }^{2}$ Department of Geriatric, the First Affiliated Hospital, Guangzhou Medical University, Guangzhou, China
}

Email address:

chenzexian@foxmail.com (Zexian Chen)

\section{To cite this article:}

Zexian Chen, Xiaosheng He, Juanni Huang, Xiaojian Wu, Ping Lan. Laparoscopic Versus Open Surgery for Rectal Cancer in Elderly Patients. Journal of Surgery. Vol. 4, No. 2, 2016, pp. 27-30. doi: 10.11648/j.js.20160402.15

Received: February 18, 2016; Accepted: March 31, 2016; Published: April 9, 2016

\begin{abstract}
With the increase of life expectancy, surgical intervention for rectal cancer is more and more frequently performed in the elderly. It is well accepted that laparoscopic surgery is of advantage, but not widely recognized in old patients with rectal cancer. In order to assess laparoscopic surgery for rectal cancer in elderly patients, we performed this study. This retrospective study was designed to compare short-term outcomes between laparoscopic surgery and open surgery in elderly patients with rectal cancer, which may give some useful guidance in the clinical practice. Thirty-seven patients with rectal cancer aged 75 and older undergoing laparoscopic surgery were matched with 37 counterparts undergoing open surgery. Criteria of matching included general information and preoperative status. Patients in the laparoscopic surgery and open surgery groups were comparable for the matching criteria. Compared with the open surgery group, estimated blood loss $(\mathrm{P}=0.048)$ and intraoperative transfusion $(\mathrm{P}=0.042)$ were less in the laparoscopic surgery group. As to short-term postoperative outcomes, duration of postoperative hospital stay was shorter $(\mathrm{P}=0.039)$ and overall complication $(\mathrm{P}=0.032)$ and wound complication $(\mathrm{P}=0.038)$ was less in the laparoscopic surgery group than in the open surgery group. In conclusion, considering the operative variables and short-term outcomes, laparoscopic surgery is safe and seems superior to open surgery in elderly patients with rectal cancer. However, further studies with more patients are needed to confirm the results and assess long-term results.
\end{abstract}

Keywords: Laparoscopic Surgery, Open Surgery, Elderly Patients, Rectal Cancer

\section{Introduction}

With the improvement in life quality and health care as well as advances in medicine, life expectancy continues to increase worldwide, leading to a higher old-aged population. For example, the life expectancy in China is about 75 years old [1]. And in America, the population over 80 years old is expected to reach 11.4 million, estimated by the US Bureau of Census [2]. Meanwhile, the incidence of colorectal diseases which need surgical intervention, especially colorectal cancer (CRC) usually increases with advancing age. As a matter of fact, about one half of patients with colorectal cancer (CRC) are over 70 years of age and CRC is the second leading cause of cancer death in this age group [3-5]. Most patients present with resectable disease [6, 7]. Surgeons usually give priority to colorectomy for CRC surgical treatment in resectable cases and colorectomy can be performed as open colorectomy and laparoscopic colorectomy. Elderly patients are often regarded as high-risk patients for major abdominal surgery because of a lack of functional reserve and associated medical comorbidities such as cardiovascular and pulmonary diseases, which may play an important role on the outcomes of surgical treatment [8-10]. Thus, surgery for the elderly with CRC is a major medical care issue.

Many published studies reported on the comparison between laparoscopic surgery and open surgery for the elderly patients in aspect of both gastrointestinal cancer and benign disease such as inflammatory bowel disease and diverticular disease and the results showed that laparoscopic surgery were safe and maybe superior [11-14]. In de Campos-Lobato's study [11], the authors focused on 3 different disease conditions including colon cancer, Crohn's disease and diverticular disease, and found that disease 
conditions did not matter the benefits of laparoscopy. Laparoscopic surgery is reported to be associated with milder immunologic and inflammatory response [15] and have decreased morbidity and mortality, faster recovery and shorter hospital stay [16, 17]. Decreased postoperative hospital stay duration always reflects faster postoperative recovery of intake of oral food, bowel function and physical activity [18-23]. As to CRC, similar resulted were found [24-26]. For example, in Issa's study [24], it comprised 93 patients aged 80 years and over who underwent colectomy for CRC between 2005 and 2008, and the result showed that hospital stay was shorter and complications were less in laparoscopic group. In Sklow's study [27], they further assessed the advantages of laparoscopic surgery for the elderly and the young and found that there was no significant difference in different age groups, showing the reliability of laparoscopic surgery in old patients. Similar study was performed by Frasson [14], who found that laparoscopy improved short-term postoperative outcome more in elderly than in younger patients. However, data about with rectal cancer specially is sparse [28, 29], let along geriatric patients. To the best of our knowledge, no similar data contraposing Chinese population is available. Therefore, we conduct this study to compare the short-term outcomes of laparoscopic surgery and open surgery for elderly patients with rectal cancer.

\section{Methods}

\subsection{Patients}

Consecutive patients aged over 75 years who underwent radical laparoscopic surgery for rectal cancer from 2007 to 2013 in the Sixth Affiliated Hospital of Sun Yat-sen University and the First Affiliated Hospital of Guangzhou Medical University were included in this retrospective study and then matched with the same number of patients who underwent radical open surgery for rectal cancer during the same period. Thus, all the eligible patients were divided into two groups, the laparoscopic surgery (LS) group and the open surgery (OS) group. Data about the preoperative status, surgical variables and short-term post-operative outcomes were obtained by careful chart review. This study was approved by the institutional review board of the two hospitals.

Uniform exclusion criteria for both groups ruled out emergency cases, patients who'd got neoadjuvant therapy, patients with recurrent rectal cancer and cases without resection of rectal. Noteworthily, conversion of LS was excluded in our study as the surgical procedure was similar to neither LS nor OS.

As for the standard of matching, patients in the OS group were selected to match with the LS group according to general information and preoperative status including age, gender, body mass index (BMI), preoperative hemoglobin level, comorbid disease, previous abdominal surgery,
American Society of Anesthesiology (ASA) score. Comorbid disease included cardiovascular, respiratory, renal disease, hypertension and diabetes, which might have some effects upon the operation. Others such as cataract were not significant and were thus ignored. Among the variables mentioned above, BMI and preoperative hemoglobin level helped to assess the nutritional status, while comorbidity factors were evaluated by comorbid disease, previous abdominal surgery and especially ASA score. This matching standard could, to some extent, avoid unnecessary bias and confounder as this study mainly focused on the comparison of the two surgical procedures.

Our attention of comparison was the surgical and postoperative evaluation. Surgical variables included type of procedure performed (LS or OS), operative time (defined as the time from incision to closure), estimated blood loss, intraoperative transfusion. Short-term postoperative outcomes, such as intensive care unit (ICU) stay, duration of postoperative hospital stay, short-term complications and reoperation because of complications, were included.

\subsection{Statistical Analysis}

Data were analyzed using the Statistical Package for Social Science software version 17.0 (SPSS Inc. Chicago, IL, USA). For all variables, descriptive statistics were conducted, including means and standard deviations or medians and ranges for continuous factors, and frequencies for categorical factors. Student's t-tests or Wilcoxon rank sum tests were used to compare continuous factors and Chi-square or Fisher's exact probability tests (if expected cell counts were fewer than 5) for categorical variables, respectively. Differences were considered with statistical significance when the two-sided $\mathrm{p}$ value was less than 0.05 .

\section{Results}

\subsection{General Information}

Totally, 74 patients were included into this study. 37 patients underwent LS for rectal cancer. Another 37 were selected into the OS group according to the matching criteria. Mean age was 77.9 years old in LS group and 79.1 in OS group ( $\mathrm{P}=0.116)$, while gender ratio was similar between the two groups $(\mathrm{P}=0.483)$. Preoperative nutritional status was comparable in these two groups, with average BIM of 22.5 and $22.0 \mathrm{~kg} / \mathrm{m} 2(\mathrm{P}=0.609)$, and average hemoglobin of 122.2 and $119.7 \mathrm{~g} / \mathrm{L}(\mathrm{P}=0.603)$ in $\mathrm{LS}$ group and $\mathrm{OS}$ group, respectively. As to preoperative comorbidity factors, $56.8 \%$ and $43.2 \%$ patients had comorbid disease $(\mathrm{P}=0.245)$ while previous abdominal surgery was similar $(\mathrm{P}=0.394)$. About one half (48.6\% and $61.1 \%$ respectively) of the patients had and ASA score of 3 or 4 . Overall, the LS group and OS group were comparable for the matched criteria. Table 1 showed the demographics and clinical characteristics of the enrolled patients, with the $\mathrm{p}$ values showing the assessment of matching. 
Table 1. Demographics and clinical characteristics of the patients.

\begin{tabular}{llll}
\hline Variable & LS group & OS group & p value \\
\hline No. of patients & 37 & 37 & - \\
Age (years) & $77.9 \pm 2.5$ & $79.1 \pm 3.8$ & 0.116 \\
Gender ratio, F/M & $22 / 15$ & $19 / 18$ & 0.483 \\
BMI $\left(\mathrm{kg} / \mathrm{m}^{2}\right)$ & $22.5 \pm 4.1$ & $22.0 \pm 3.3$ & 0.609 \\
Hemoglobin $(\mathrm{g} / \mathrm{L})$ & $122.2 \pm 18.2$ & $119.7 \pm 20.3$ & 0.603 \\
Comorbid disease & $21(56.8 \%)$ & $16(43.2 \%)$ & 0.245 \\
Previous abdominal surgery & $4(10.8 \%)$ & $2(5.4 \%)$ & 0.394 \\
ASA score, $\mathrm{I} / \mathrm{II} / \mathrm{III} / \mathrm{IV}$ & $1 / 17 / 16 / 1$ & $0 / 14 / 22 / 0$ & 0.358 \\
TNM stage, $1 / 2 / 3 / 4$ & $7 / 13 / 14 / 3$ & $6 / 13 / 15 / 3$ & 0.905 \\
\hline
\end{tabular}

$\mathrm{LS}=$ laparoscopic surgery, $\mathrm{OS}=$ open surgery, $\mathrm{F}=$ female, $\mathrm{M}=$ male, $\mathrm{BMI}=$ body mass index, ASA= American Society of Anesthesiology. Values are expressed as mean \pm standard deviation or median (range), or as number (percentage).

\subsection{Surgical Variables}

Laparoscopic surgery was averagely 28 min longer than open surgery, without significant difference ( 235 vs. 207 min, $\mathrm{P}=0.139$ ). In the LS group, estimated blood was significantly lower than the OS group (100 vs. $200 \mathrm{ml}$, $\mathrm{P}=0.048$ ), so was the number of patients needing intraoperative transfusion $(9.1 \%$ vs. $25.7 \%, \mathrm{P}=0.042)$. Surgical variables were showed in Table 2.

Table 2. Surgical variables.

\begin{tabular}{llll}
\hline Variable & LS group & OS group & p value \\
\hline Operative time (min) & $235.4 \pm 83.8$ & $207.7 \pm 67.9$ & 0.139 \\
Estimated blood loss $(\mathrm{ml})$ & $100(30-1000)$ & $200(30-3000)$ & $0.048^{*}$ \\
Intraoperative transfusion & $3(9.1 \%)$ & $9(25.7 \%)$ & $0.042 *$ \\
\hline
\end{tabular}

$\mathrm{LS}=$ laparoscopic surgery, $\mathrm{OS}=$ open surgery. Values are expressed as mean \pm standard deviation or median (range), or as number (percentage).*Result with statistical significance.

\subsection{Postoperative Evaluation}

The frequency of ICU stay was same between the two groups. Postoperative hospital stay duration (14.5 vs. 19.9 days, $\mathrm{P}=0.039$ ) were significantly decreased in the LS group. The overall complication rates were $27.0 \%$ for LS and $51.4 \%$ for OS ( $\mathrm{P}=0.032)$, and wound complication including wound infection and wound disruption occurred markedly more frequently in the OS group $(0 \%$ vs. $8.1 \%, \mathrm{P}=0.038)$. Complications other than wound complication were comparable between LS and OS. Seven patients ( 2 in LS group and 5 in $\mathrm{OS}$ group, $\mathrm{P}=0.2$ ) required reoperation due to postoperative complications. The causes for reoperation included anastomotic fistula $(\mathrm{n}=1)$, intestinal obstruction $(\mathrm{n}=1)$, hernia $(\mathrm{n}=2)$, stoma failure $(\mathrm{n}=2)$ and secondary sutures for wound infection or disruption $(\mathrm{n}=1)$. Reoperation was similar between the two groups. Table 3 shows the evaluation of postoperative outcomes.
Table 3. Postoperative evaluation.

\begin{tabular}{llll}
\hline Variable & LS group & OS group & p value \\
\hline ICU stay & $10(27.0 \%)$ & $10(27.0 \%)$ & 1.000 \\
Hospital stay (day) & $14.5(7-46)$ & $19.9(9-93)$ & $0.039^{*}$ \\
Complication & & & \\
Overall & $10(27.0 \%)$ & $19(51.4 \%)$ & $0.032^{*}$ \\
Wound & $0(0 \%)$ & $3(8.1 \%)$ & $0.038^{*}$ \\
Abdominal infection & $2(5.4 \%)$ & $2(5.4 \%)$ & 1.000 \\
Intestinal obstruction & $2(5.4 \%)$ & $2(5.4 \%)$ & 1.000 \\
Anastomotic fistula & $1(2.7 \%)$ & $2(5.4 \%)$ & 0.556 \\
Hernia & $1(2.7 \%)$ & $2(5.4 \%)$ & 0.556 \\
Cardiovascular & $0(0 \%)$ & $1(2.7 \%)$ & 0.314 \\
Respiratory & $1(2.7 \%)$ & $4(10.8 \%)$ & 0.165 \\
Stoma & $1(2.7 \%)$ & $1(2.7 \%)$ & 1.000 \\
Reoperation & $2(5.4 \%)$ & $5(13.5 \%)$ & 0.233 \\
\hline
\end{tabular}

$\mathrm{LS}=$ laparoscopic surgery, $\mathrm{OS}=$ open surgery, $\mathrm{ICU}=$ intensive care unit. Values are expressed as mean \pm standard deviation or median (range), or as number (percentage).*Result with statistical significance.

\section{Conclusion}

Considering the operative variables and short-term outcomes, laparoscopic surgery in old patients with rectal cancer turn out to be with less estimated blood loss, less need of intraoperative transfusion, shorter duration of postoperative hospital stay and less complications. Our study prove that laparoscopic surgery is safe and superior to open surgery in elderly patients with rectal cancer, which may provide some guidance in clinical practice. However, in the treatment of cancer, the oncologic results in term of long-term survival and recurrence are the most important, so further studies with more patients are needed to confirm the results and assess long-term results.

\section{Acknowledgements}

This work was performed by the authors listed above and generous support was given by the relevant departments such as the record room and database department.

\section{References}

[1] Yang G, Wang Y, Zeng Y, Gao GF, Liang X, Zhou M, Wan X, Yu S, Jiang Y, Naghavi M, Vos T, Wang H, Lopez AD, Murray CJ. Rapid health transition in China, 1990-2010: findings from the Global Burden of Disease Study 2010. LANCET 2013; 381: 1987-2015.

[2] U.S. Bureau of the Census (2008) Annual estimates of the resident population by sex and five-year age groups for the United States. Retrieved 21 July 2009 at http://www.census.gov/popest/national/asrh/NC-EST2008/NC -EST2008-01.xls. Vintage 2008.

[3] Levi F, Lucchini F, Negri E, Boyle P, La Vecchia C. Changed trends of cancer mortality in the elderly. ANN ONCOL 2001; 12: 1467-1477. 
[4] Folprecht G, Cunningham D, Ross P, Glimelius B, Di Costanzo F, Wils J, Scheithauer W, Rougier P, Aranda E, Hecker H, Kohne CH. Efficacy of 5-fluorouracil-based chemotherapy in elderly patients with metastatic colorectal cancer: a pooled analysis of clinical trials. ANN ONCOL 2004; 15: $1330-1338$.

[5] Franceschi S, La Vecchia C. Cancer epidemiology in the elderly. Crit Rev Oncol Hematol 2001; 39: 219-226.

[6] Ng O, Watts E, Bull CA, Morris R, Acheson A, Banerjea A. Colorectal cancer outcomes in patients aged over 85 years. Ann R Coll Surg Engl 2016; 98: 216-221.

[7] Braendegaard WS, Baatrup G, Pfeiffer P, Qvortrup C. Trends in colorectal cancer in the elderly in Denmark, 1980-2012. ACTA ONCOL 2016; 55 Suppl 1:29-39.

[8] Whittle J, Steinberg EP, Anderson GF, Herbert R. Results of colectomy in elderly patients with colon cancer, based on Medicare claims data. AM J SURG 1992; 163: 572-576.

[9] Longo WE, Virgo KS, Johnson FE, Oprian CA, Vernava AM, Wade TP, Phelan MA, Henderson WG, Daley J, Khuri SF. Risk factors for morbidity and mortality after colectomy for colon cancer. DIS COLON RECTUM 2000; 43: 83-91.

[10] Black P, Kathiresan S, Chung W. Meningioma surgery in the elderly: a case-control study assessing morbidity and mortality. Acta Neurochir (Wien) 1998; 140: 1013-1016, 1016-1017.

[11] de Campos-Lobato LF, Alves-Ferreira PC, Geisler DP, Kiran RP. Benefits of laparoscopy: does the disease condition that indicated colectomy matter? Am Surg 2011; 77: 527-533.

[12] Law WL, Chu KW, Tung PH. Laparoscopic colorectal resection: a safe option for elderly patients. J Am Coll Surg 2002; 195: 768-773.

[13] Grailey K, Markar SR, Karthikesalingam A, Aboud R, Ziprin $\mathrm{P}$, Faiz O. Laparoscopic versus open colorectal resection in the elderly population. SURG ENDOSC 2013; 27: 19-30.

[14] Frasson M, Braga M, Vignali A, Zuliani W, Di Carlo V. Benefits of laparoscopic colorectal resection are more pronounced in elderly patients. DIS COLON RECTUM 2008; 51: $296-300$.

[15] Sylla P, Kirman I, Whelan RL. Immunological advantages of advanced laparoscopy. Surg Clin North Am 2005; 85: 1-18.

[16] Kang CY, Chaudhry OO, Halabi WJ, Nguyen V, Carmichael JC, Stamos MJ, Mills S. Outcomes of laparoscopic colorectal surgery: data from the Nationwide Inpatient Sample 2009. AM J SURG 2012; 204: 952-957.

[17] Orcutt ST, Marshall CL, Robinson CN, Balentine CJ, Anaya DA, Artinyan A, Awad SS, Berger DH, Albo D. Minimally invasive surgery in colon cancer patients leads to improved short-term outcomes and excellent oncologic results. AM J SURG 2011; 202: 528-531.
[18] Lian L, Kalady M, Geisler D, Kiran RP. Laparoscopic colectomy is safe and leads to a significantly shorter hospital stay for octogenarians. SURG ENDOSC 2010; 24: 2039-2043.

[19] Pinto RA, Ruiz D, Edden Y, Weiss EG, Nogueras JJ, Wexner SD. How reliable is laparoscopic colorectal surgery compared with laparotomy for octogenarians? SURG ENDOSC 2011; 25 2692-2698.

[20] Feng B, Zheng MH, Mao ZH, Li JW, Lu AG, Wang ML, Hu WG, Dong F, Hu YY, Zang L, Li HW. Clinical advantages of laparoscopic colorectal cancer surgery in the elderly. AGING CLIN EXP RES 2006; 18: 191-195.

[21] Vignali A, Di Palo S, Tamburini A, Radaelli G, Orsenigo E, Staudacher C. Laparoscopic vs. open colectomies in octogenarians: a case-matched control study. DIS COLON RECTUM 2005; 48: 2070-2075.

[22] Delgado S, Lacy AM, Garcia VJ, Balague C, Pera M, Salvador L, Momblan D, Visa J. Could age be an indication for laparoscopic colectomy in colorectal cancer? SURG ENDOSC 2000; 14: 22-26.

[23] Kapritsou M, Korkolis DP, Konstantinou EA. Open or laparoscopic surgery for colorectal cancer: a retrospective comparative study. GASTROENTEROL NURS 2013; 36: $37-41$.

[24] Issa N, Grassi C, Melki Y, Powsner E, Dreznik Z. Laparoscopic colectomy for carcinoma of the colon in octogenarians. J GASTROINTEST SURG 2011; 15: 2011-2015.

[25] Bilimoria KY, Bentrem DJ, Merkow RP, Nelson H, Wang E, Ko CY, Soper NJ. Laparoscopic-assisted vs. open colectomy for cancer: comparison of short-term outcomes from 121 hospitals. J GASTROINTEST SURG 2008; 12: 2001-2009.

[26] Nakamura T, Onozato W, Mitomi H, Naito M, Sato T, Ozawa $\mathrm{H}$, Hatate K, Ihara A, Watanabe M. Retrospective, matched case-control study comparing the oncologic outcomes between laparoscopic surgery and open surgery in patients with right-sided colon cancer. SURG TODAY 2009; 39: 1040-1045.

[27] Sklow B, Read T, Birnbaum E, Fry R, Fleshman J. Age and type of procedure influence the choice of patients for laparoscopic colectomy. SURG ENDOSC 2003; 17: 923-929.

[28] Law WL, Lee YM, Choi HK, Seto CL, Ho JW. Laparoscopic and open anterior resection for upper and mid rectal cancer: an evaluation of outcomes. DIS COLON RECTUM 2006; 49: 1108-1115.

[29] Barlehner E, Benhidjeb T, Anders S, Schicke B. Laparoscopic resection for rectal cancer: outcomes in 194 patients and review of the literature. SURG ENDOSC 2005; 19: 757-766. 